\title{
Management of Cerebral Metastases from Melanoma Treated at a Single Institution
}

\section{Manejo de metástases cerebrais de melanoma tratadas em uma única instituição}

\author{
Michael Ricardo Lang ${ }^{1}$ Luis Renato Garcez de Oliveira Mello ${ }^{2}$ Vitor Hugo Boer ${ }^{3}$ \\ Celso Itiberê Bernardes ${ }^{4}$ Leandro José Haas ${ }^{4}$ Danielle De Lara ${ }^{4}$ Lucas Eduardo Bonadio ${ }^{1}$ \\ Felipe Laurindo Cabral ${ }^{1}$ Gabriel Hoher Peres ${ }^{1}$ Edson Machado Shirai Missugiro ${ }^{5}$ \\ Renann Vicenzoto de Castro e Souza ${ }^{5}$
}

1 MR, Neurosurgery, Hospital Santa Isabel, Universidade Regional de Blumenau, Santa Catarina, Brazil

2 Professor, Neurosurgery, Chief of Clinic Surgery, Head for Neurosurgery Residency, Hospital Santa Isabel, Universidade Regional de Blumenau, Santa Catarina, Brazil

3 Professor, Neurosurgery, Chief of Neurologic Surgery, Hospital Santa Isabel, Universidade Regional de Blumenau, Santa Catarina, Brazil

4 Neurosurgeon, Hospital Santa Isabel, Blumenau, Santa Catarina, Brazil

5 MD, Academic, Universidade Regional de Blumenau, Blumenau, Santa Catarina, Brazil

Arq Bras Neurocir 2015;34:116-121.

\section{Abstract \\ Keywords \\ - metastatic melanoma \\ - brain metastases \\ - neurosurgery}

Address for correspondence Michael Ricardo Lang, MD, Hospital Santa Isabel, Universidade Regional de Blumenau, SC, Brazil (e-mail: michael.r.lang@hotmail.com).
Objective This retrospective study aimed to analyze prognostic factors, effects of treatment, and survival outcome of patients with brain metastasis from melanoma at a single institution over the last 22 years.

Methods Study transversal retrospective of 34 patients with brain metastases from melanoma, histologically proven, surgically treated by the Department of Neurosurgery at the Hospital Santa Isabel, Blumenau, over 22 years.

Results The median patient age was 50 years and $67.6 \%$ of the patients were men. Most patients (70.6\%) had a single cerebral metastasis and $29.4 \%$ had two three injuries. Twenty percent of the patients in this series had evidence of extracranial metastasis. The KPS at presentation was $\geq 70$ in 12 patients (35.2\%). Evidence of recurrent intracranial melanoma was found during follow-up review in $17.6 \%$ of patients. The overall median survival time from diagnosis of cerebral metastasis was 14.4 months. The absence of extracranial metastasis was associated with a significantly prolonged survival ( $p=0.052)$, as was adjuvant therapy $(p=0.02)$.

Conclusion The early diagnosis, with total resection of melanoma metastasis and association of adjuvant therapies showed a positive influence on survival. However, the number of lesions and extracranial disease decreased the survival rates. received

August 28, 2014

accepted

March 31, 2015
DOI http://dx.doi.org/ $10.1055 / \mathrm{s}-0035-1554897$ ISSN 0103-5355.
Copyright $\odot 2015$ by Thieme Publicações License terms Ltda, Rio de Janeiro, Brazil

(c) $(1) \$$ 


\section{Resumo}

Palavras-chave
- melanoma
metastático
- metástase cerebral
-
neurocirurgia

Objetivo O objetivo deste estudo retrospectivo foi analisar os fatores prognósticos, os efeitos do tratamento e a sobrevida de pacientes com metástase cerebral de melanoma em uma única instituição ao longo dos últimos 22 anos.

Métodos Estudo transversal retrospectivo de 34 pacientes com metástases cerebrais de melanoma, histologicamente comprovadas, tratados cirurgicamente pelo Departamento de Neurocirurgia do Hospital Santa Isabel de Blumenau, em 22 anos.

Resultados A média de idade dos pacientes foi de 50 anos e $67,6 \%$ deles eram homens. A maioria dos pacientes (70,6\%) tinha uma única metástase cerebral e $29,4 \%$ tiveram duas e três lesões; $20 \%$ dos pacientes desta série apresentaram evidência de metástase extracraniana. O KPS na apresentação foi $\geq 70$ em 12 pacientes (35,2\%). Evidência de recidiva intracraniana foi encontrada durante a revisão em 17,6 \% dos pacientes. O tempo de sobrevida global média do diagnóstico de metástase cerebral foi de 14,4 meses. A ausência de metástases extracranianas foi associada a uma sobrevida significativamente maior $(p=0,052)$, assim como a terapia adjuvante $(p=0,02)$. Conclusão O diagnóstico precoce, a ressecção total da metástase do melanoma e a associação de terapias adjuvantes mostraram um efeito positivo sobre a sobrevida. Por outro lado, o número de lesões e de doenças extracranianas diminuiu as taxas de sobrevida.

\section{Introduction}

Cutaneous melanoma is one of the most common tumors to metastasize $(8 \%)$ to the brain; is currently the third most common cause of cerebral metastasis, after lung (17\%), renal cell (10.5\%), and breast (5.2\%) cancers; and is the most common cancer in young adults in Australia and in many other Western countries, with an estimated lifetime risk of between $1: 25$ and $1: 87 .^{1-5}$ Large clinical series show that brain metastasis (BM) are diagnosed in 10 to $40 \%$ of melanoma patients during their lifetime, and autopsy data demonstrate that 49 to $73 \%$ of patients who die of disseminated metastatic melanoma have brain involvement. ${ }^{4,6,7}$ Improvements in imaging quality and accessibility have also contributed to the increased number of patients in whom metastasis is diagnosed. ${ }^{2}$

Melanoma has a propensity for multiorgan involvement, and central nervous system complications are frequent. Metastatic spread to the brain is the most serious event in the course of melanoma because it carries the worst prognosis of all visceral metastasis and represents the major cause of death in patients with disseminated disease. ${ }^{6}$ The prognosis of patients with disseminated melanoma is particularly poor if cerebral metastasis is present. ${ }^{5,8}$

The recent management of cerebral melanoma metastasis mainly depends on the number and size of the metastases and on extracranial extension of the disease. Neurosurgery or stereotactic radiosurgery (STR) is usually offered to patients with single or few metastatic lesions. However, surgical removal is a mainstay. Patients who are not eligible for surgery or STR are usually offered whole-brain radiotherapy (WBRT), although no survival advantage has been demon- strated to date. ${ }^{1,2,6}$ Nevertheless, surgical resection in conjunction with WBRT is feasible in a subgroup of these patients and may prolong their survival. ${ }^{5,8}$ Generally accepted standards for the application of different treatment modalities in patients with BM from melanoma do not exist so far. Oncologists had little to offer, given that chemotherapy generally does not penetrate the blood-brain barrier. ${ }^{9}$

This retrospective study aimed to analyze prognostic factors, effects of treatment, and survival outcome of patients with BM from melanoma at a single institution over the last 22 years.

\section{Clinical Material and Methods}

From January 1991 to April 2013, total 34 patients with histologically proven cerebral metastasis from melanoma underwent surgical treatment in the Department of Neurosurgery at the Santa Isabel Hospital. Most patients lived in Blumenau, with small numbers living in other cities around. Clinical data on these patients were collected retrospectively from their medical records, including operative and pathologic reports, and information from the office files of their neurosurgeons. Detailed follow-up review was conducted by telephone contact with patients our family members. The following information was obtained: demographic, time interval between diagnoses of primary melanoma and BM, localization and number of BM, Karnofsky performance status (KPS), presence of extracranial disease, administered treatment, response to treatment, date of death or last follow-up, and cause of death.

Diagnosis of BM from melanoma was based on computed tomography (CT) and magnetic resonance imaging (MRI) 
scans. Usually, patients were offered surgery if they had one or few surgically accessible BM and good KPS. STR was not available in our department. Patients, who received WBRT, usually commencing within 6 weeks of surgery, were treated with a total dose of $30 \mathrm{~Gy}$ with different fractionations regimens. Systemic chemotherapy was administered at some time after craniotomy, mainly for progressive extracranial disease.

Follow-up images were obtained by the neurosurgeon by using CT and MRI scans were obtained in patients being considered for reoperation.

\section{Statistical Analysis}

Kaplan-Meier survival curves and median values were calculated by standard formulas with commercially available software (EPINFO, 2006 e EPIDATA). A comparison of the median survival times among treatment groups was performed using log-rank tests. Standard tests of multivariate and univariate analysis were performed using the test with Bartlett's Test for Inequality of Population Variances and parametric test ANOVA, and test for two samples MannWhitney/Wilcoxon 13 Statistical significance was defined at the $5 \%$ level.

\section{Results}

The demographic profile of the patients included in the study is summarized in - Table $\mathbf{1}$. The median patient age was 50 years (range, 23-68 years) and 67.6\% of the patients were men. A history of melanoma was found in 16 patients (47\%), with a median interval of 12.2 months from diagnosis of primary melanoma. The remaining 18 patients (53\%) presented with a cerebral metastasis as the first evidence of melanoma.

Table 1 Demographic features in 34 patients who underwent craniotomy for cerebral metastasis of melanoma

\begin{tabular}{|c|c|}
\hline Variable & No of patients (\%) \\
\hline \multicolumn{2}{|c|}{ Age in years } \\
\hline $23-29$ & $8(23.3)$ \\
\hline $30-49$ & $8(23.3)$ \\
\hline $50-68$ & $18(53.3)$ \\
\hline \multicolumn{2}{|l|}{ Sex } \\
\hline M & $23(67.6)$ \\
\hline $\mathrm{F}$ & $11(32.4)$ \\
\hline \multicolumn{2}{|c|}{ Time at initial diagnosis until cerebral metastases in months } \\
\hline$<1^{\mathrm{a}}$ & $18(53)$ \\
\hline $1-6$ & $6(17.6)$ \\
\hline $7-12$ & $3(8.9)$ \\
\hline $13-24$ & $3(8.9)$ \\
\hline$>24$ & $4(11.6)$ \\
\hline
\end{tabular}

${ }^{a}$ Melanoma was diagnosed following presentation with cerebral metastasis.
Table 2 Characteristics of 34 patients with cerebral metastasis of melanoma

\begin{tabular}{|l|l|l|}
\hline Variable & $\begin{array}{l}\text { No. of } \\
\text { patients (\%) }\end{array}$ & $\begin{array}{l}\text { Median } \\
\text { survival (mo) }\end{array}$ \\
\hline \multicolumn{2}{|l|}{ Karnofsky at presentation } & $p=0.0940$ \\
\hline $0-60$ & $22(64.7)$ & 3 \\
\hline $70-100$ & $12(35.3)$ & 35.2 \\
\hline No. of metastasis & $p=0.487$ \\
\hline 1 & $24(70.6)$ & 21 \\
\hline 2 & $5(14.7)$ & 3.4 \\
\hline$\geq 3$ & $5(14.7)$ & 3.4 \\
\hline Location of metastasis & $31(91)$ & 14.3 \\
\hline Supratentorial & $3(9)$ & 15 \\
\hline Infratentorial & $7(20.6)$ & 1.42 \\
\hline Extracranial metastasis & $27(79.4)$ & 17.57 \\
\hline yes & $27(79.4)$ & 17.57 \\
\hline no & $2(6)$ & 3.5 \\
\hline Extent of extracranial metastases & 0 \\
\hline Skin ${ }^{\text {a }}$ & $1(2.6)$ & 1 \\
\hline Lung & $2(6)$ & 1 \\
\hline Liver, lung & $2(6)$ & 0.0528 \\
\hline Liver & 279 \\
\hline Paravertebral, spinal cord & 2.3 \\
\hline
\end{tabular}

The clinical characteristics of all patients at the time their cerebral metastasis was diagnosed are presented in -Table 2. Most patients (70.6\%) had a single cerebral metastasis. This was assessed using CT scanning only over the period of 1991 through 1998 and by MRI beginning in 1998. Of the remainder, $14.7 \%$ had two metastases and the same number had three metastases; $91 \%$ of the patients had supratentorial lesions. The locations of single cerebral lesions were frontal (50\%), parietal (5\%), temporal (40\%), and occipital (1\%). Overall, more than $20 \%$ of the patients in this series had evidence of extracranial metastasis at the time their cerebral metastatic disease was diagnosed. The KPS at presentation was $\geq 70$ in 12 patients (35.2\%).

The treatment details for the cerebral metastases and patient outcome are given in -Table 3. A macroscopically complete tumor excision was achieved in $38.3 \%$ of patients. Subtotal resection or biopsy sampling were performed in the remainder, based on an assessment by the surgeon at the time of the procedure. Most patients (64.7\%) had either improved or unchanged neurologic status when assessed at the time of discharge from the hospital.

Clinical or radiologic evidence of recurrent intracranial melanoma was found during follow-up review in $17.6 \%$ of patients. Recurrence was assessed using CT scanning, followed by MRI if further surgical treatment was contemplated. Radiosurgery was not available for the patients in this series. 
Table 3 Treatment of cerebral metastases in 34 patients with melanoma

\begin{tabular}{|c|c|c|}
\hline Variable & $\begin{array}{l}\text { No. of } \\
\text { patients (\%) }\end{array}$ & Survival (mo) \\
\hline \multicolumn{2}{|l|}{ Treatment } & $p=0.02$ \\
\hline Surgery & $13(38.3)$ & 1.9 \\
\hline Surgery/WBRT & $4(11.7)$ & 11.2 \\
\hline Surgery/chemo & $13(38.3)$ & 24.8 \\
\hline Surgery/WBRT/chemo & $4(11.7)$ & 21.5 \\
\hline \multicolumn{2}{|l|}{ Extent of resection } & $p=0.08$ \\
\hline $\begin{array}{l}\text { Macroscopically } \\
\text { complete }\end{array}$ & $13(38.3)$ & 15 \\
\hline Subtotal & $4(11.7)$ & 46.7 \\
\hline Biopsy only & $8(23.5)$ & 3.3 \\
\hline$N A^{a}$ & $9(26.5)$ & \\
\hline \multicolumn{2}{|l|}{ Neurologic status } & $p=0.0002$ \\
\hline Improved & $13(38.2)$ & 34.4 \\
\hline Unproved & $12(35.3)$ & 1.1 \\
\hline Unchanged & $9(26.5)$ & 2 \\
\hline \multicolumn{2}{|l|}{ Intracranial recurrence } & $p=0.5$ \\
\hline Op site & $0(0.0)$ & 0 \\
\hline Same lobe & $4(11.7)$ & 4.75 \\
\hline Adjacent lobe & $2(5.9)$ & 8 \\
\hline None & $28(82.4)$ & 15.9 \\
\hline \multicolumn{2}{|l|}{ Outcome } & $p=0.04$ \\
\hline Alive w/melanoma & $1(2.9)$ & 12 \\
\hline $\begin{array}{l}\text { Death from } \\
\text { disseminated } \\
\text { melanoma }\end{array}$ & $11(32.4)$ & 37.7 \\
\hline $\begin{array}{l}\text { Death from } \\
\text { intracerebral } \\
\text { metastases }\end{array}$ & $22(64.7)$ & 2.9 \\
\hline
\end{tabular}

Abbreviations: NA, not applicable; WBRT, whole-brain radiotherapy.

\section{Survival in months (\%)}

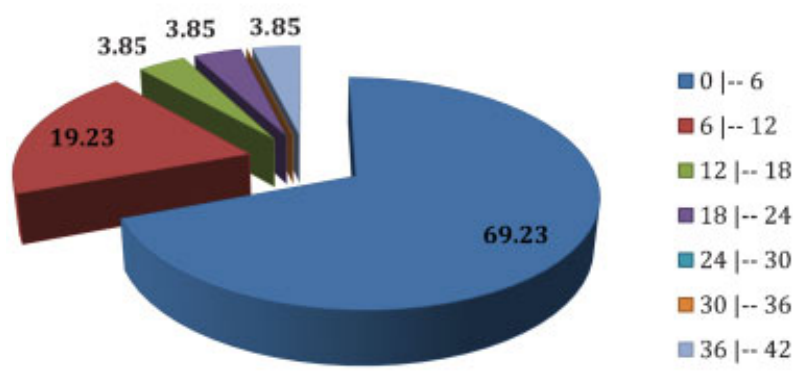

Fig. 1 Survival in months. *The overall median survival time from diagnosis was 14.4 months.

Progressive intracerebral melanoma was the direct cause of death in $64.7 \%$ of the entire series. The remainder died of progressive extracranial disease.

The overall median survival time from diagnosis of cerebral metastasis was 14.4 months, which is demonstrated in - Fig. 1. On univariate analysis, the absence of extracranial metastasis was associated with a significantly prolonged survival $(p=0.052)$, as was adjuvant therapy $(p=0.02)$. Other factors that did not affect survival included patient age, sex, the time interval from primary melanoma to cerebral metastasis, and the location of the cerebral lesion (infraor supratentorial).

Although the median survival of patients with single lesions was higher (21 months), there was no statistical significance $(p=0.48)$ (-Fig. 2 ).

\section{Discussion}

Melanoma has the highest propensity to metastasize to the brain of all primary neoplasms in adults, and this paper shows that the most prevalent age range is between 50 and
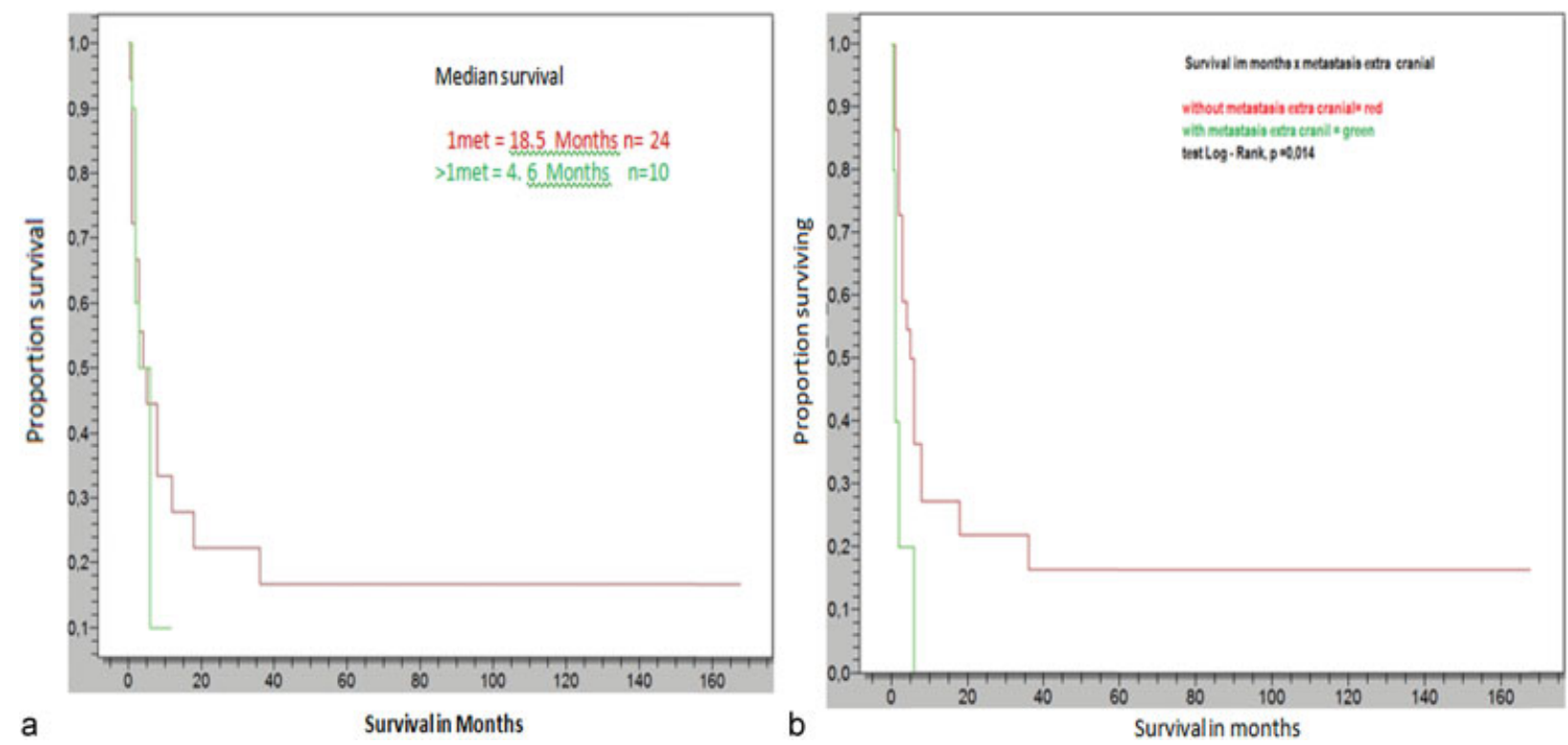

Fig. 2 (a) Kaplan-Meier curve for survival in patients with one or more lesions and (b) patients with or without extracranial metastasis. 
69 years (53.3\%). This population is affected in their productive age, aggressive therapy contributes impressively in some cases. Patients with melanoma tend to be younger ( $\sim 50$ years old) and often have excellent KPS scores on admission; however, our study found that KPS less than 70 were most frequent (64.7\%) and the patients was oldest (50-69 years old). ${ }^{10}$

In this series, there was early diagnosis of BM, on average 12.2 months after diagnosis of the primary disease, which typically occurs late in the course of melanoma, with an interval from 2.2 to 3.8 years. In the study of Wronski et al, the median time from diagnosis of the primary tumor to that of the BM was 14.4 months. ${ }^{4,6,11-13}$

In addition, Sampson et al investigated that patients with a single lesion and an absence of extracranial metastasis who initially presented with BM have a better prognosis. This article was evidenced that the most significant determinant of survival is the absence of extracranial disease (17.34 menses), unlike those who had extracranial disease (1.42). The same was asserted by Nieder et al that patients with extracranial metastasis had a poor median survival (3.2 months). ${ }^{10,11,14,15}$

Nieder et al asserted that the most important prognostic factor was KPS. ${ }^{10}$ Their study showed a poor survival (2 months) for patients with KPS $<70$ years. In this study, all patients had BM initially and their survival was 3.28 months with KPS $<70$ years. Both data Sampson and Nieder had the same from database. ${ }^{10,11}$

The number of brain lesions from melanoma is a factor prognostic used in the scores of assessment of melanoma, like melanoma-specific graded prognostic assessment (GPA), and this article confirms that patients with two to three or more than three BMs had a poor prognosis with 3.4 months. ${ }^{10,16-18}$

In the study of Wronski and Arbit, the 1 -year mortality of patients who underwent craniotomy was $60 \%$, whereas our results show higher mortality (70.6\%) for the overall group, without discrimination of other variables. ${ }^{4}$

The survival of supratentorial and infratentorial was 14.3 and 15 months, respectively; however, as other studies show, the location of cerebral metastasis was not significant in survival.

The primary goal of surgery is gross-total resection of the tumor with minimal disruption of, or injury to, the brain. In some cases, the additional goal of debulking and relief of mass effect are considered. Account of the criterion of the extent of resection during surgery is a subjective evaluation of the surgeon, and our team has four members, because this is not statistically significant if resection is macroscopically complete or subtotal and de survival $(p=0.08)$. Although the mortality of patients who underwent biopsy only was 3.3 months, per Zacest et al showed that a macroscopically complete excision significantly affected survival on univariate analysis $(p<0.05)$. Thus, the improvement in the technology and techniques of resection should be craved in our institution. 2,5,19

Combining the modalities of surgery, WBRT, and chemotherapy has improved in a statistically significant survival (21.5 months) for patients who underwent these three therapies $(p=0.02){ }^{13,20-24}$

\section{Conclusion}

The early diagnosis, with total resection of melanoma metastasis and association of adjuvant therapies, showed a positive influence on survival. However, the number of lesions and extracranial disease decreased the survival rates. We believe that further studies will follow protocols to establish treatment.

\section{References}

1 Staudt M, Lasithiotakis K, Leiter U, et al. Determinants of survival in patients with brain metastases from cutaneous melanoma. $\mathrm{Br} \mathrm{J}$ Cancer 2010;102(8):1213-1218

2 Ranasinghe MG, Sheehan JM. Surgical management of brain metastases. Neurosurg Focus 2007;22(3):E2

3 Sloan AE, Nock CJ, Einstein DB. Diagnosis and treatment of melanoma brain metastasis: a literature review. Cancer Contr 2009;16(3):248-255

4 Wroński M, Arbit E. Surgical treatment of brain metastases from melanoma: a retrospective study of 91 patients. J Neurosurg 2000;93(1):9-18

5 Zacest AC, Besser M, Stevens G, Thompson JF, McCarthy WH, Culjak G. Surgical management of cerebral metastases from melanoma: outcome in 147 patients treated at a single institution over two decades. J Neurosurg 2002;96(3):552-558

6 Eigentler TK, Figl A, Krex D, et al; Dermatologic Cooperative Oncology Group and the National Interdisciplinary Working Group on Melanoma. Number of metastases, serum lactate dehydrogenase level, and type of treatment are prognostic factors in patients with brain metastases of malignant melanoma. Cancer 2011;117(8):1697-1703

7 Lonser RR, Song DK, Klapper J, et al. Surgical management of melanoma brain metastases in patients treated with immunotherapy. J Neurosurg 2011;115(1):30-36

8 Javalkar V, Cardenas R, Ampil F, Ahmed O, Shi R, Nanda A. The Louisiana State University experience in the management of single small cerebellar metastasis. Neurosurgery 2010;67(6): 1515-1522

9 Sheehan J, Sheehan J. Changing paradigms for the treatment of brain metastasis. Neurosurg Focus 2007;22(3):E (Intro)

10 Nieder C, Marienhagen K, Geinitz H, Grosu AL. Can current prognostic scores reliably guide treatment decisions in patients with brain metastases from malignant melanoma? J Cancer Res Ther $2011 ; 7(1): 47-51$

11 Sampson JH, Carter JH Jr, Friedman AH, Seigler HF. Demographics, prognosis, and therapy in 702 patients with brain metastases from malignant melanoma. J Neurosurg 1998;88(1):11-20

12 Choi KN, Withers HR, Rotman M. Intracranial metastases from melanoma. Clinical features and treatment by accelerated fractionation. Cancer 1985;56(1):1-9

13 Fife KM, Colman MH, Stevens GN, et al. Determinants of outcome in melanoma patients with cerebral metastases. J Clin Oncol 2004;22(7):1293-1300

14 Liew DN, Kano H, Kondziolka D, et al. Outcome predictors of Gamma Knife surgery for melanoma brain metastases. J Neurosurg 2011;114(3):769-779

15 Morris SL, Low SH, A'Hern RP, et al. A prognostic index that predicts outcome following palliative whole brain radiotherapy for patients with metastatic malignant melanoma. Br J Cancer 2004;91(5):829-833

16 Sperduto PW, Kased N, Roberge D, et al. Summary report on the graded prognostic assessment: an accurate and facile diagnosis-specific tool to estimate survival for patients with brain metastases. J Clin Oncol 2012;30(4): 419-425 
17 Raizer JJ, Hwu WJ, Panageas KS, et al. Brain and leptomeningeal metastases from cutaneous melanoma: survival outcomes based on clinical features. Neuro Oncol 2008;10(2): 199-207

18 Davies MA, Liu P, McIntyre S, et al. Prognostic factors for survival in melanoma patients with brain metastases. Cancer 2011; 117(8):1687-1696

19 Moser RP, Johnson ML. Surgical management of brain metastases: how aggressive should we be? Oncology (Williston Park) 1989; 3(6):123-127, discussion 128, 134

20 Brand CU, Ellwanger U, Stroebel W, et al. Prolonged survival of 2 years or longer for patients with disseminated melanoma. An analysis of related prognostic factors. Cancer 1997;79(12):2345-2353
21 Brega K, Robinson WA, Winston K, Wittenberg W. Surgical treatment of brain metastases in malignant melanoma. Cancer 1990;66(10):2105-2110

22 Mintz AH, Kestle J, Rathbone MP, et al. A randomized trial to assess the efficacy of surgery in addition to radiotherapy in patients with a single cerebral metastasis. Cancer 1996;78(7):1470-1476

23 Noordijk EM, Vecht CJ, Haaxma-Reiche $H$, et al. The choice of treatment of single brain metastasis should be based on extracranial tumor activity and age. Int J Radiat Oncol Biol Phys 1994; 29(4):711-717

24 Patchell RA, Tibbs PA, Walsh JW, et al. A randomized trial of surgery in the treatment of single metastases to the brain. $\mathrm{N}$ Engl J Med 1990;322(8):494-500 